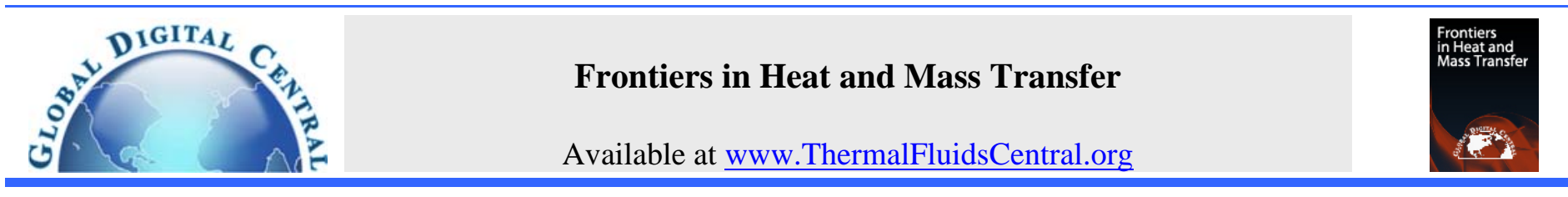

\title{
G-JITTER EFFECTS ON THE MIXED CONVECTION FLOW OF NANOFLUID PAST AN INCLINED STRETCHING SHEET
}

\author{
Noraihan Afiqah Rawi ${ }^{\mathrm{a}}$, Abdul Rahman Mohd Kasim ${ }^{\mathrm{b}}$,Zaiton Mat Isa ${ }^{\mathrm{a}}$, Aurangzaib Mangi ${ }^{\mathrm{c}}$, Sharidan Shafie ${ }^{\mathrm{a}, *}$ \\ ${ }^{a}$ Department of Mathematical Sciences, Faculty of Science, Universiti Teknologi Malaysia, 81310 UTM Johor Bahru, Johor, Malaysia \\ ${ }^{b}$ Faculty of Industrial Science \& Technology, Universiti Malaysia Pahang, Lebuhraya Tun Razak, 26300 Gambang, Pahang, Malaysia \\ ${ }^{c}$ Department of Mathematical Sciences, Federal Urdu University of Arts, Science \& Technology, Gulshan-e-Iqbal Campus, Karachi, Pakistan
}

\begin{abstract}
Mixed convection flows of nanofluid past an inclined stretching sheet with g-jitter effect is studied in this paper. Water based nanofluid containing copper, copper oxide, aluminium oxide and silver nanoparticles are concerned. Coupled nonlinear partial differential equations are solved using Kellerbox method. The effect of solid nanoparticles volume fraction parameter, frequency of oscillation and inclination angle parameter is observed to reduce the skin friction and heat transfer coefficients whereas mixed convection parameter increases both skin friction and heat transfer coefficients. Present study also shows that, the heat transfer coefficient is highest for silver nanofluid.
\end{abstract}

Keywords: gravity modulation, numerical solution, solid nanoparticles.

\section{INTRODUCTION}

The boundary layer flow and heat transfer over a stretching sheet are encountered in a numerous industrial engineering applications such as fiber technology, production of sheeting materials, polymer extrusion and emergency shutdown conditions. In the past few years, convective heat transfer in nanofluid has become a major contemporary interest in fluid flow studies. Nanofluid can be described as a fluid containing nanometer sized particles, whereas these fluids are engineered colloidal suspensions of nanoparticles in a base fluid. Basically, the idea of nanofluid demonstrated by the suspension of nanometer sized particles in the convectional heat transfer fluids including oil, water and ethylene glycol mixture which have a low thermal conductivity. The concept of nanofluid has been introduced to develop an advanced heat transfer fluids with substantially higher conductivities to enhance the thermal characteristics. The pioneering study was carried out by Choi (1995) and Choi et al. (2001) successfully showed that the addition of a small amount of nanoparticles to convectional heat transfer liquids increased the thermal conductivity of the fluid up to approximately two times. Then, Khanafer et al. (2003) investigated the heat transfer performance of nanofluid inside an enclosure taking into account the solid particle dispersion.

Since the discovering of the importance of nanofluid throughout these pioneering experimental studies, many researchers had involved in the study of this field particularly in the study of boundary layer flow problem in nanofluid. Numerous models have been proposed to study the convective flows of nanofluid, including the most popular models suggested by Buongiorno (2006) and Tiwari and Das (2007). Buongiorno (2006) suggested the effect of Brownian motion and thermophoresis while the nanofluid model proposed by Tiwari and Das (2007) analyzed the behaviour of nanofluid by taking the solid nanoparticles volume fraction as a parameter. It is worth mentioning that both of proposed nanofluid models were recently used by Kuznetsov and Nield (2010);
Khan and Pop (2010); Vajravelu et al. (2011); Chamkha and Rashad (2012); Qasim et al. (2013); Anwar et al. (2014) in their papers. For example, Yirga and Shankar (2015) carried out an analysis of the effects of viscous dissipation and chemical reactions on the magnetohydrodynamics flow and heat transfer of nanofluid through a porous media using Tiwari and Das model. They showed that, the increasing of nanoparticles volume fraction leads to increase the thermal boundary layer thickness and decrease the velocity boundary layer thickness for both considered water based nanofluid, copper and silver. However, all the above studies were restricted in the steady state conditions. In reality, unsteady boundary layer plays important roles in many engineering problems like start-up process and periodic fluid motion. Unsteady boundary layer has different behaviour due to the extra time-dependent terms, which will influence the fluid motion pattern and the boundary layer separation (Tamim et al. (2013)). Recently, Uddin et al. (2014) investigated the effects of g-jitter on the unsteady mixed convective boundary layer flow of nanofluid past a permeable stretching sheet associated with the effects of linear hydrodynamic slip, thermal slip and temperature dependent viscosity.

The presence of a gravitational field and a temperature gradient usually can generate buoyancy convective flows in many situations, most probably in the low gravity or microgravity environment. In this environment, it has been found that, buoyancy-driven fluid flows and sedimentations are greatly reduced, allowing systems to work under purely diffusive conditions. For example, low gravity situation can provided an environment conductive to growing crystals with more uniform solute distribution and/or in a diffusion controlled regime. However, aboard orbiting spacecraft, all objects experience lowamplitude perturbed accelerations, or g-jitter, caused by crew activities, orbiter maneuvers, equipment vibrations, solar drag and other sources (Antar and Nuotio-Antar (1993); Hirata et al. (2001)) which make it difficult to achieve diffusion controlled single crystal growth in space. G-Jitter or also known as periodical gravity modulation can be defined as the inertia effects due to quasi-steady, oscillatory or transient 
accelerations arising from crew motions and machinery vibrations in parabolic aircrafts, space shuttles or other microgravity environments. Recently, this adverse effect of g-jitter has received attention of many researchers focusing on the convective flow in various conditions and geometries. There have been a number of studies which investigate the behavior of g-jitter with different effects and fluids focusing on boundary layer flow were conducted by Rees and Pop (2000; 2001) and Sharidan et al. (2005; 2006; 2007). Very recently, Uddin et al. (2015) investigated the boundary layer flow of g-jitter induced mixed convection of nanofluid past a vertical surface and taking into account the effect of constant convective thermal and mass boundary conditions using Buongiorno-Darcy porous medium model. Motivated from the cited literature, it seems that no research has been reported on the boundary layer flow on nanofluid past an inclined stretching sheet. Following Sharidan et al. (2006), the gravity acceleration is takes the form,

$$
g^{*}(t)=g_{0}[1+\varepsilon \cos (\pi \omega t)] \mathbf{k}
$$

where $g_{0}$ is the time-averaged value of the gravitational acceleration, $g^{*}(t)$ acting along the direction on the unit vector $\mathbf{k}$ which is oriented in the upward direction, $\varepsilon$ is a scaling parameter, which gives the magnitude of the gravity modulation relative to $g_{0}, t$ is the time and $\omega$ is the frequency of oscillation of the g-jitter driven flow.

The main contribution of this paper is to investigate the effect of gjitter associated with the presence of chosen solid nanoparticles on the mixed convection flow in viscous and incompressible fluid past an inclined stretching sheet. The basic governing equations are closely followed the previous studies done by Mahdy (2012) using Tiwari and Das model which is highlighted the effects of solid nanoparticles volume fraction with the additional effects of g-jitter. Water-based nanofluid containing copper $(\mathrm{Cu})$, copper oxide $(\mathrm{CuO})$, aluminium oxide $\left(\mathrm{Al}_{2} \mathrm{O}_{3}\right)$ and silver (Ag) are taken into consideration. The governing nonlinear partial differential equations are first transformed into non-dimensional forms and then solved numerically using the Keller-box method which are practically used by many researchers (Kasim et al. (2012); Aurangzaib et al. (2013); Rawi et al. (2014)). The effects of frequency of oscillation, amplitude of modulation, inclination angle, solid nanoparticles volume fraction and mixed convection parameters have been discussed and the results are graphically displayed.

\section{MATHEMATICAL FORMULATION}

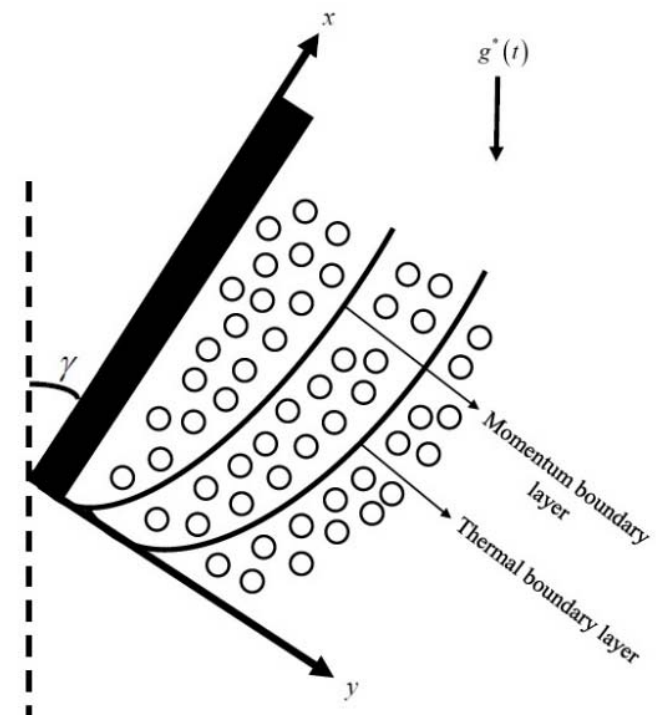

Fig. 1 Physical model and coordinate system
Consider the mixed convection flow of a viscous and incompressible nanofluid containing $\mathrm{Cu}, \mathrm{CuO}, \mathrm{Al}_{2} \mathrm{O}_{3}$ and $\mathrm{Ag}$ nanoparticles along an inclined stretching sheet with the presence of g-jitter. Figure 1 depicts the physical model and coordinate system of the problem, where the $x$-axis is taken along the surface with the inclination angle, $\gamma$ to the vertical and $y$-axis is taken normal to the surface. Following Buongiorno (2006), nanofluid is considered as two component mixtures with the following assumptions:

$\begin{array}{ll}\text { i. } & \text { no chemical reaction; } \\ \text { ii. negligible viscous dissipation; } \\ \text { iii. nano-solid-particles and base fluid are in thermal } \\ \text { equilibrium. }\end{array}$

In this problem, it is assumed that, the plate is moving in the $x$ direction of the flow with a linear velocity, $u_{w}(x)$ and the temperature of the plate, $T_{w}(x)$ varies linearly with the distance $x$ along the surface, where $T_{w}(x)>T_{\infty}$ with $T_{\infty}$ being the uniform temperature of the ambient nanofluid.

Under the Boussinesq and boundary layer approximations, the governing equations of unsteady mixed convection flow of nanofluid model past an inclined stretching sheet including the conservation of mass, momentum and thermal energy equation can be written as (Tiwari and Das (2007)),

$$
\begin{gathered}
\frac{\partial u}{\partial x}+\frac{\partial v}{\partial y}=0 \\
\rho_{n f}\left[\frac{\partial u}{\partial t}+u \frac{\partial u}{\partial x}+v \frac{\partial u}{\partial y}\right]=\mu_{n f} \frac{\partial^{2} u}{\partial y^{2}}+g^{*}(t)(\rho \beta)_{n f}\left(T-T_{\infty}\right) \cos \gamma \\
\left(\rho C_{p}\right)_{n f}\left[\frac{\partial T}{\partial t}+u \frac{\partial T}{\partial x}+v \frac{\partial T}{\partial y}\right]=k_{n f} \frac{\partial^{2} T}{\partial y^{2}},
\end{gathered}
$$

where $u$ and $v$ are the velocity components along $x$ and $y$ axes, $t$ is the time, and $T$ is the nanofluid temperature. Further, $\rho_{n f}$ is the density of nanofluid, $\mu_{n f}$ is the dynamic viscosity of nanofluid, $\beta_{n f}$ is the thermal expansion of nanofluid, $\left(\rho C_{p}\right)_{n f}$ is the heat capacitance of nanofluid, where $C_{p}$ is the specific heat at constant pressure, and $k_{n f}$ is the effective thermal conductivity of the nanofluid, respectively. Here, the nanofluid constants are defined as,

$$
\begin{gathered}
\rho_{n f}=(1-\phi) \rho_{f}+\phi \rho_{s},(\rho \beta)_{n f}=(1-\phi)(\rho \beta)_{f}+\phi(\rho \beta)_{s}, \\
\left(\rho C_{p}\right)_{n f}=(1-\phi)\left(\rho C_{p}\right)_{f}+\phi\left(\rho C_{p}\right)_{s},
\end{gathered}
$$

and the effective thermal conductivity of nanofluid approximated by the Maxwell-Garnetts model is given as

$$
k_{n f}=k_{f} \frac{\left(k_{s}+2 k_{f}\right)-2 \phi\left(k_{f}-k_{s}\right)}{\left(k_{s}+2 k_{f}\right)+\phi\left(k_{f}-k_{s}\right)}
$$

while the viscosity of nanofluid has been approximated by Brinkman (1952) is given as

$$
\mu_{n f}=\frac{\mu_{f}}{(1-\phi)^{2.5}}
$$

where $\phi$ is the solid nanoparticles volume fraction of the nanofluid. As mentioned by Wang et al. (1999), the expression (5) is restricted only to the spherical nanoparticles, where it does not account for the other shapes of nanoparticles. The subscripts $f$ and $s$ refer to base fluid and nanoparticles properties, respectively.

The appropriate initial and boundary conditions are,

$$
\begin{aligned}
& t=0: u=v=0, T=T_{\infty} \text { for any } x, y, \\
& t>0: u=u_{w}(x), v=0, T=T_{w} \text { at } y=0, \\
& u \rightarrow 0, T \rightarrow T_{\infty} \text { as } y \rightarrow \infty .
\end{aligned}
$$


In this problem, the continuous stretching sheet is assumed to have the velocity and temperature in the form of $u_{w}(x)=c x$ and $T_{w}=T_{\infty}+a x$ where $a$ and $c$ are constants with $c>0$.

The complexity of the problem is reduced by introducing the following similarity transformations (Sharidan et al. (2006)),

$$
\psi=\left(c v_{f}\right)^{1 / 2} x f(\tau, \eta), \theta(\tau, \eta)=\frac{\left(T-T_{\infty}\right)}{\left(T_{w}-T_{\infty}\right)}, \tau=\omega t, \eta=\left(\frac{c}{v_{f}}\right)^{1 / 2} y,
$$

where $v_{f}$ is the effective kinematic viscosity of base fluid and $\psi(x, y)$ is the stream function defined as $u=\frac{\partial \psi}{\partial y}$ and $v=-\frac{\partial \psi}{\partial x}$ which is identically satisfies Eq. (1). By employing the similarity transformations (8) into Eqs. (1) to (3), the following transformed governing equations are obtained,

$$
\begin{aligned}
& \frac{1}{(1-\phi)^{2.5}} \frac{\partial^{3} f}{\partial \eta^{3}}+C_{1}\left[f \frac{\partial^{2} f}{\partial \eta^{2}}-\left(\frac{\partial f}{\partial \eta}\right)^{2}\right] \\
& +C_{2} \lambda[1+\varepsilon \cos (\pi \tau)] \theta \cos \gamma \quad=C_{1} \Omega \frac{\partial^{2} f}{\partial \tau \partial \eta}, \\
& \frac{k_{n f}}{k_{f}} \frac{\partial^{2} \theta}{\partial \eta^{2}}+C_{3} \operatorname{Pr}\left[f \frac{\partial \theta}{\partial \eta}-\frac{\partial f}{\partial \eta} \theta\right]=C_{3} \operatorname{Pr} \Omega \frac{\partial \theta}{\partial \tau},
\end{aligned}
$$

where the constants $\mathrm{C}_{1}, \mathrm{C}_{2}$ and $\mathrm{C}_{3}$ are defined as,

$$
C_{1}=(1-\phi)+\phi \frac{\rho_{s}}{\rho_{f}}, C_{2}=(1-\phi)+\phi \frac{(\rho \beta)_{s}}{(\rho \beta)_{f}}, C_{3}=(1-\phi)+\phi \frac{\left(\rho C_{p}\right)_{s}}{\left(\rho C_{p}\right)_{f}} \text {, }
$$

and the boundary conditions (4) become

$$
\begin{gathered}
f=0, \frac{\partial f}{\partial \eta}=1, \theta=1 \text { at } \eta=0, \\
\frac{\partial f}{\partial \eta} \rightarrow 0, \theta \rightarrow 0 \text { as } \eta \rightarrow \infty .
\end{gathered}
$$

Here, $\Omega=\frac{\omega}{c}$ is the non-dimensional frequency, $\operatorname{Pr}=\left(\frac{C_{p} \mu}{k}\right)_{f}$ is the Prandtl number, and $\lambda=\frac{G r_{x}}{\operatorname{Re}_{x}^{2}}$ is the mixed convection parameter with $G r_{x}=g_{0} \beta_{f}\left[T_{w}(x)-T_{\infty}\right] x^{3} / v_{f}^{2}$ and $\operatorname{Re}_{x}=u_{w}(x) x / v_{f}$ as the local Grashof and Reynolds numbers, respectively. It is worth mentioning that, $\lambda>0$ corresponds to assisting flow and $\lambda<0$ for opposing flow.

The physical quantities of principal interest are the skin friction coefficient, $C_{f}$, and the local Nusselt number, $N u_{x}$ are defined respectively as

$$
C_{f}=\frac{\tau_{w}(x)}{\rho_{f} u_{w}^{2}} \text { and } N u_{x}=\frac{q_{w}(x) x}{k_{f}\left(T_{w}-T_{\infty}\right)}
$$

where $\tau_{w}(x)$ is the wall shear stress and $q_{w}(x)$ is the wall heat flux are given by,

$$
\tau_{w}=\mu_{n f}\left(\frac{\partial u}{\partial y}\right)_{y=0} \text { and } q_{w}(x)=-k_{n f}\left(\frac{\partial T}{\partial y}\right)_{y=0} .
$$

Here, $k_{n f}$ and $\mu_{n f}$ being the thermal conductivity and dynamic viscosity of nanofluid. Using (8), the following skin friction coefficient and local Nusselt number are obtained as follows,

$$
C_{f} \operatorname{Re}_{x}^{1 / 2}=\frac{1}{(1-\phi)^{2.5}} \frac{\partial^{2} f}{\partial \eta^{2}}(\tau, 0), \frac{N u_{x}}{\operatorname{Re}_{x}^{1 / 2}}=-\frac{k_{n f}}{k_{f}} \frac{\partial \theta}{\partial \eta}(\tau, 0) .
$$

\section{METHODS}

The system of the partial differential equations, (9) and (10) together with the boundary conditions (11) are solved numerically using an implicit finite scheme known as Keller-box method which is described in details by Cebeci and Bradshaw (1984). Basically, the idea of Keller-box method is to reduce the governing system of equations to the form of a first order system. At first, the differential equation are reduced to a first order system and discretize into finite difference form by using central differences. Then, Newton's method is used to linearize the resulting equations and employed on the coefficient of matrix of the finite difference equations. Finally, the linear system is solved using blocktriadiagonal elimination method.

In this problem, all the results were obtained using uniform grids in both $\tau$ and $\eta$ directions where the grid size of $\Delta \eta$ is taken as 0.02 and $\Delta \tau$ is taken as 0.01 so that, the numerical values obtained are independent of $\Delta \eta$ and $\Delta \tau$ (see Table 1). The satisfaction of the outer boundary condition is achieved by considering the boundary layer thickness, $\eta_{\infty}=6$. Convergence criterion is set to $10^{-5}$ which gives accuracy to four decimal places.

Table 1 Values of $f^{\prime \prime}(0)$ for $\varepsilon=\Omega=1, \phi=0.1, \gamma=\frac{\pi}{6}$ and $\operatorname{Pr}=6.2$ at different grid size

\begin{tabular}{ccc}
\hline$\Delta \eta$ & $\Delta \tau$ & $f^{\prime \prime}(0)$ \\
\hline 0.02 & 0.01 & 1.085973 \\
0.03 & 0.02 & 1.085973 \\
0.04 & 0.03 & 1.085973 \\
0.05 & 0.04 & 1.085973 \\
\hline
\end{tabular}

Following Sharidan et al. (2006), the values of $\varepsilon$ considered in the range of $0 \leq \varepsilon \leq 1$ due to the reason that, the values of $\varepsilon>>1$ is equivalent to have the perceived gravity reverse its direction over part of the g-jitter cycle. The computation for the appropriate steady solutions is always started with $\varepsilon=0$ (constant gravity) and convergence to a steady periodic state was demanded to have taken place when max $\left|\theta^{\prime}(\tau, 0)-\theta^{\prime}(\tau-2,0)\right|<10^{-5}$ over the whole period.

\section{RESULTS AND DISCUSSIONS}

The transformed differential equations (9) and (10) subjected to the boundary conditions (11) have been solved numerically using Keller-box method. In this problem, four different types of nanofluid containing of $\mathrm{Cu}, \mathrm{CuO}, \mathrm{Al}_{2} \mathrm{O}_{3}$ and Ag-water nanoparticles are chosen to analyze the effects of solid nanoparticles volume fraction, $\phi$, amplitude of modulation, $\varepsilon$, frequency of oscillation, $\Omega$, inclination angle, $\gamma$, and mixed convection parameter, $\lambda$. Thermophysical properties of base fluid and nanoparticles is presented in Table 2 (Turkyilmazoglu and Pop (2013)).

Table 2 Thermophysical properties of base fluid and nanoparticles.

\begin{tabular}{cccccc}
\hline \multirow{2}{*}{$\begin{array}{c}\text { Physical } \\
\text { properties }\end{array}$} & $\begin{array}{c}\text { Base } \\
\text { fluid }\end{array}$ & \multicolumn{4}{c}{ Nanoparticles } \\
\cline { 2 - 6 } & Water & $\mathrm{Cu}$ & $\mathrm{Al}_{2} \mathrm{O}_{3}$ & $\mathrm{CuO}$ & $\mathrm{Ag}$ \\
\hline$C_{p}(\mathrm{~J} / \mathrm{kg} \mathrm{K})$ & 4179 & 385 & 765 & 531.8 & 235 \\
$\rho\left(\mathrm{kg} / \mathrm{m}^{3}\right)$ & 997.1 & 8933 & 3970 & 6320 & 10500 \\
$k(\mathrm{~W} / \mathrm{mK})$ & 0.613 & 401 & 40 & 76.5 & 429 \\
$\beta \times 10^{5}\left(\mathrm{~K}^{-1}\right)$ & 21 & 1.67 & 0.85 & 1.80 & 1.89 \\
\hline
\end{tabular}

Referring to the previous study done by Uddin et al. (2014), the values of $\phi$ considered in the range of $0 \leq \phi \leq 0.2$. The validation of the present results has been verified with the case of viscous fluid, 
( $\phi=0)$ at the steady state flow, $(\varepsilon=\Omega=0)$ presented by Sharidan $e t$ al. (2006), Mahdy (2012) and Freidoonimehr (2015). The comparison results are exhibited in Table 3. It can be seen from this table that, a good agreement between the results exist which gives confidence in the numerical method employed. From the table, it is clearly showed, that, the heat transfer rate increases with Prandtl number. For the present results, the values of Prandtl number and frequency of oscillation have been fixed as $\operatorname{Pr}=6.2$ and $\Omega=0.2$. It is noted that, $\mathrm{Cu}$ nanoparticles is used in all figures which focus on the influence of controlling parameters on the reduced skin friction, $f^{\prime \prime}(\tau, 0)$ and heat transfer coefficient,

$-\theta^{\prime}(\tau, 0)$.

Table 3 Comparison results of the heat transfer rate, $\theta^{\prime}(0)$ for various values of

Pr at $\varepsilon=\Omega=\phi=\lambda=\gamma=0$.

\begin{tabular}{ccccc}
\hline $\operatorname{Pr}$ & $\begin{array}{c}\text { Sharidan } \text { et al. } \\
(2006)\end{array}$ & $\begin{array}{c}\text { Mahdy } \\
(2012)\end{array}$ & $\begin{array}{c}\text { Freidoonimehr } \\
(2015)\end{array}$ & Present \\
\hline 0.01 & 0.0197 & 0.01999 & - & 0.01999 \\
0.72 & 0.8086 & 0.80868 & 0.8086 & 0.8086 \\
1.0 & 1.0000 & - & 1.0000 & 1.0000 \\
3.0 & 1.9237 & - & 1.9237 & 1.9238 \\
\hline
\end{tabular}

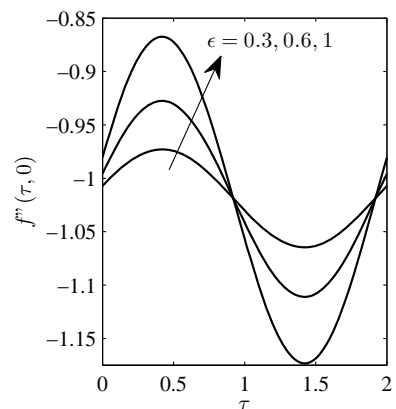

(a)

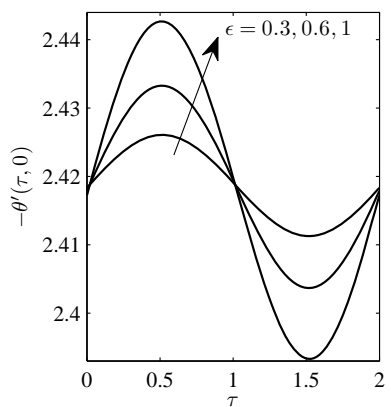

(b)
Fig. 2 Variation of $f^{\prime \prime}(\tau, 0)$ and $-\theta^{\prime}(\tau, 0)$ for different values of $\varepsilon$ at $\gamma=\frac{\pi}{6}, \lambda=1$ and $\phi=0.1$.

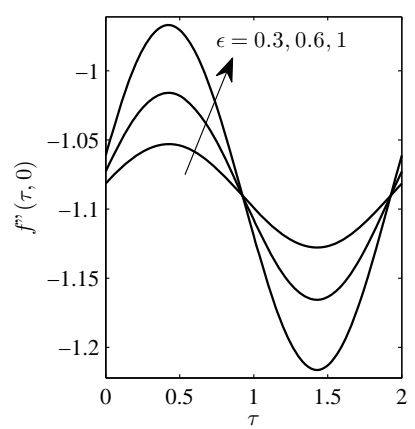

(a)

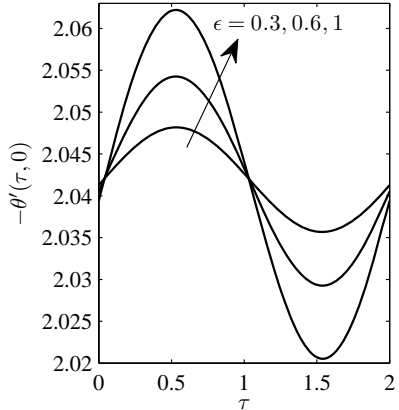

(b)
Fig. 3 Variation of $f^{\prime \prime}(\tau, 0)$ and $-\theta^{\prime}(\tau, 0)$ for different values of $\varepsilon$ at $\gamma=\frac{\pi}{6}, \lambda=1$ and $\phi=0.2$.

Figures 2 and 3 show the effect of $\phi$ on the variation of reduced skin friction, $f^{\prime \prime}(\tau, 0)$ and heat transfer coefficient, $-\theta^{\prime}(\tau, 0)$ with different values of $\varepsilon$. It is observed that, an increase in $\phi$ decreases the values of $f^{\prime \prime}(\tau, 0)$ and $-\theta^{\prime}(\tau, 0)$. Physically, an increase in the value of $\phi$ raises the effective viscosity as well as the thermal conductivity of nanofluid. As a result, the thermal boundary layer thickness and the temperature gradient at the wall decrease.

Figures 4 to 7 depict the influence of on the variation of $f^{\prime \prime}(\tau, 0)$ and $-\theta^{\prime}(\tau, 0)$ for different values of $\Omega, \gamma$ and $\lambda$. All figures show that, the effect of increasing in $\varepsilon$ is giving an almost proportional increase and decrease in $f^{\prime \prime}(\tau, 0)$ and $-\theta^{\prime}(\tau, 0)$, respectively. It can also be observe that, the effect of $\Omega$ on the change in $\varepsilon$ for $-\theta^{\prime}(\tau, 0)$ is seen to be more substantial compared to $f^{\prime \prime}(\tau, 0)$. Figures $4 \mathrm{a}$ and $4 \mathrm{~b}$ indicate that the values of $f^{\prime \prime}(\tau, 0)$ and $-\theta^{\prime}(\tau, 0)$ decrease with the increasing of $\Omega$. Meanwhile, the corresponding curves of variation of $f^{\prime \prime}(\tau, 0)$ and $-\theta^{\prime}(\tau, 0)$ in Figures $2 \mathrm{a}$ to $6 \mathrm{~b}$ show an identical trend where the upper peak occur near $\tau=0.5$ and lower peak at $\tau=1.5$ except for Figure $4 \mathrm{~b}$. The corresponding curves for $-\theta^{\prime}(\tau, 0)$ in Figure $4 \mathrm{~b}$ change as the values of $\Omega$ increases where the upper peak occur near $0.5 \leq \tau \leq 1$ and lower peak at $1.5 \leq \tau \leq 2$. As reported by Rees and Pop (2001), at low values of $\Omega$, the response on the time periodic flow is quasi static and the whole flow and temperature field is determined by the size of the perceived gravitational acceleration at any point in time. However, when the values of $\Omega$ increases, the peak response is delayed progressively and the amplitude of the variation of the response over a period also decreases as depicted in Figure 4.

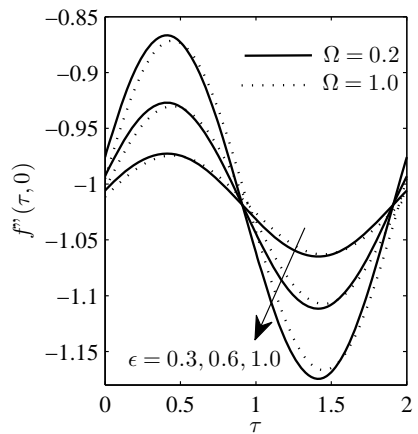

(a)

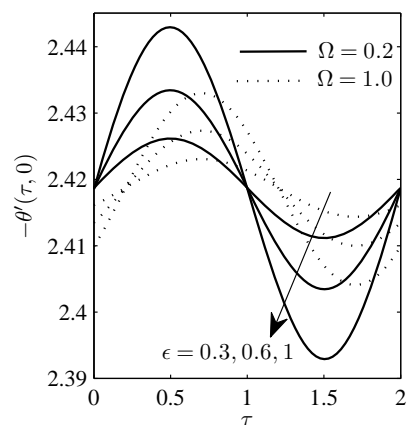

(b)
Fig. 4 Variation of $f^{\prime \prime}(\tau, 0)$ and $-\theta^{\prime}(\tau, 0)$ for different values of $\varepsilon$ and $\Omega$ at $\gamma=\frac{\pi}{6}$ and $\lambda=1$

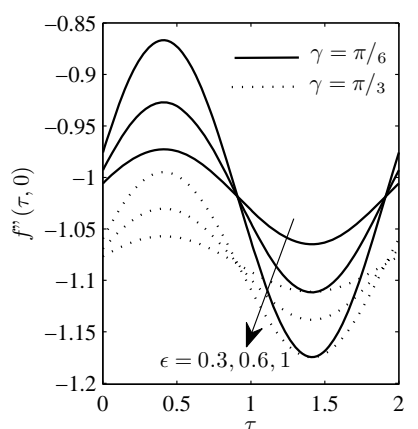

(a)

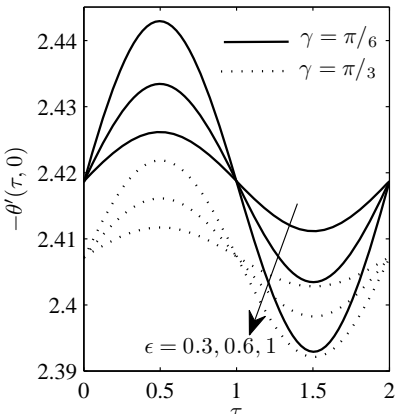

(b)
Fig. 5 Variation of $f^{\prime \prime}(\tau, 0)$ and $-\theta^{\prime}(\tau, 0)$ for different values of $\varepsilon$ and $\gamma$ at $\Omega=0.2$ and $\lambda=1$.

Further, the effect of $\gamma$ on the variation of $f^{\prime \prime}(\tau, 0)$ and $-\theta^{\prime}(\tau, 0)$ are shown in Figure 5. Both Figures 5a and 5b exhibit that the increasing of $\gamma$ lead to reduce the values of $f^{\prime \prime}(\tau, 0)$ and $-\theta^{\prime}(\tau, 0)$. This behaviour happens due to the fact that as the plate is inclined from the vertical cause the reduction on the buoyancy force. Meanwhile, Figures 6 and 7 show 
the influence of $\lambda$ with the different values of $\varepsilon$ on the time-periodic flow. These figures show that the variation of $f^{\prime \prime}(\tau, 0)$ and $-\theta^{\prime}(\tau, 0)$ increase with the increasing of $\lambda$ for both assisting, $\lambda>0$ and opposing flows, $\lambda<0$. Moreover, it can be observed from Figure 7 that, the corresponding curve of variation of $f^{\prime \prime}(\tau, 0)$ and $-\theta^{\prime}(\tau, 0)$ change where the upper peak occur near $\tau=1.5$ and lower peak at $\tau=0.5$.

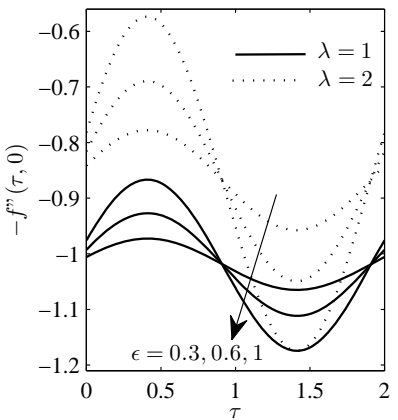

(a)

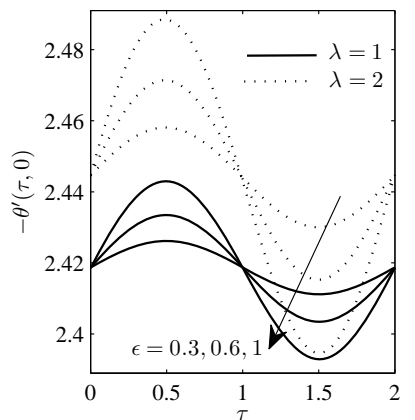

(b)
Fig. 6 Variation of $f^{\prime \prime}(\tau, 0)$ and $-\theta^{\prime}(\tau, 0)$ for different values of $\varepsilon$ and $\lambda(>0)$ at $\gamma=\frac{\pi}{6}$ and $\Omega=0.2$.

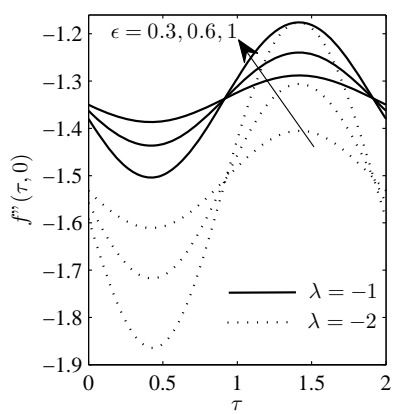

(a)

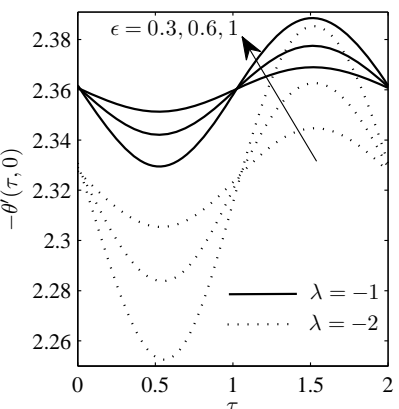

(b)
Fig. 7 Variation of $f^{\prime \prime}(\tau, 0)$ and $-\theta^{\prime}(\tau, 0)$ for different values of $\varepsilon$ and $\lambda(<0)$

$$
\text { at } \gamma=\frac{\pi}{6} \text { and } \Omega=0.2 \text {. }
$$

Table 3 Values of $f^{\prime \prime}(\tau, 0)$ and $-\theta^{\prime}(\tau, 0)$ for different values of $\phi$ and types

\begin{tabular}{cccc}
\multicolumn{4}{c}{ of nanoparticles at $\tau=0}$. \\
\hline Nanoparticles & $\phi$ & $f^{\prime \prime}(\tau, 0)$ & $-\theta^{\prime}(\tau, 0)$ \\
\hline \multirow{2}{*}{$\mathrm{Cu}$} & 0.0 & -0.764940 & -2.907997 \\
& 0.1 & -0.980502 & -2.417247 \\
$\mathrm{CuO}$ & 0.2 & -1.061210 & -2.039437 \\
& 0.0 & -0.764940 & -2.907997 \\
& 0.1 & -0.892462 & -2.444296 \\
$\mathrm{Al}_{2} \mathrm{O}_{3}$ & 0.2 & -0.933854 & -2.079679 \\
& 0.0 & -0.764940 & -2.907997 \\
& 0.1 & -0.810659 & -2.462303 \\
$\mathrm{Ag}$ & 0.2 & -0.811367 & -2.106043 \\
& 0.0 & -0.764940 & -2.907997 \\
& 0.1 & -1.025739 & -2.372838 \\
& 0.2 & -1.123934 & -1.964957 \\
\hline
\end{tabular}

Figure 8 presents the variation of $f^{\prime \prime}(\tau, 0)$ and $-\theta^{\prime}(\tau, 0)$ with respect to $\phi$ for different types of nanoparticles. Different water-based nanofluid containing $\mathrm{Cu}, \mathrm{CuO}, \mathrm{Al}_{2} \mathrm{O}_{3}$ and $\mathrm{Ag}$ are taken specifically for this result, respectively. It is observed that, $f^{\prime \prime}(\tau, 0)$ and $-\theta^{\prime}(\tau, 0)$ decrease with the increasing of $\phi$. Based on Table 1, it can be clearly seen that, Ag and $\mathrm{Al}_{2} \mathrm{O}_{3}$ have the maximum and minimum densities between the different considered types of nanoparticles. Therefore, this values lead to the minimum and maximum amount of $\left|f^{\prime \prime}(\tau, 0)\right|$ for $\mathrm{Al}_{2} \mathrm{O}_{3}$ and Ag which depicted in Figure 8a. In addition, it can be noticed from the Figure 8b that, Ag has the highest rate of $\theta^{\prime}(\tau, 0)$ due to the largest thermal conductivity value compared to the others nanoparticles considered. (Also see Table 3)

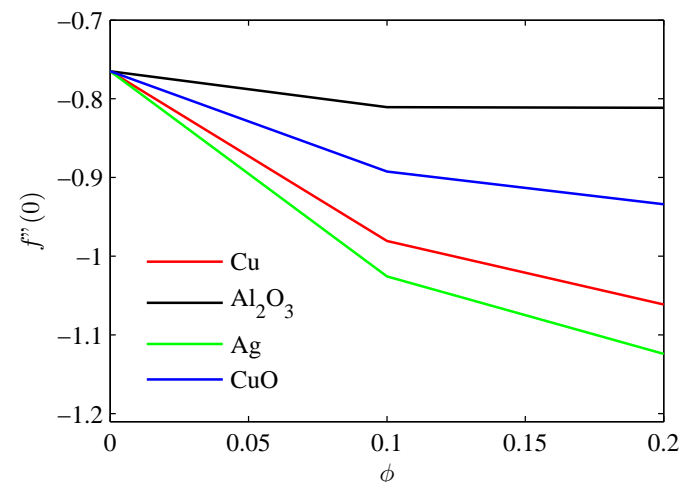

(a)

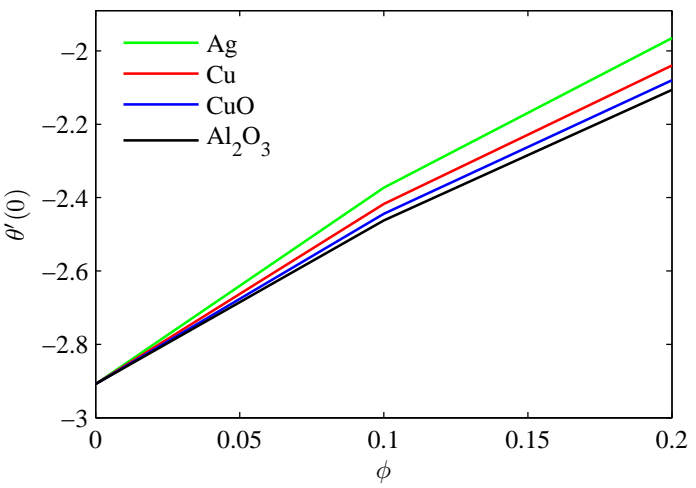

(b)

Fig. 8 Variation of $f^{\prime \prime}(\tau, 0)$ and $\theta^{\prime}(\tau, 0)$ with respect to $\phi$ at $\Omega=0.2, \lambda=1$ and $\gamma=\frac{\pi}{6}$ for different types of nanoparticles.

\section{CONCLUSIONS}

The problem of mixed convection flow of nanofluid past an inclined stretching sheet with the presence of g-jitter has been presented in this paper. The governing partial differential equations were transformed using suitable similarity transformation and solved numerically using Keller-box method. Four different types of nanoparticles including copper, copper oxide, aluminum oxide, and silver have been chosen in this study. Comparison of the results with the previously reported work shows a very good agreement for the case of viscous fluid. It was found that, the increasing of frequency of oscillation, solid nanoparticles volume fraction and inclination angle parameters lead to decrease the values of the reduced skin friction and heat transfer coefficient. Meanwhile, the opposite behaviour is obtained when the mixed convection parameter is considered for both cases, assisting and opposing flows. In addition, it can also be concluded that, a silver-water nanofluid has a higher heat transfer coefficient compared to other types of nanofluid; copper, alumina and copper oxide-water nanofluid.

\section{ACKNOWLEDGEMENTS}

The author would like to acknowledge Ministry of Higher Education (MOHE), Research Management Centre-UTM, Universiti Teknologi Malaysia (UTM) and Universiti Malaysia Pahang (UMP) for the financial support through vote numbers $15 \mathrm{H} 80,4 \mathrm{~F} 713$ and $13 \mathrm{H} 74$ for this research. 


\section{NOMENCLATURE}

$C_{f} \quad$ skin friction coefficient

$C_{p} \quad$ specific heat at constant pressure $(\mathrm{J} / \mathrm{kg} \cdot \mathrm{K})$

$g_{0} \quad$ time-averaged value of gravitational acceleration

$g^{*}(t) \quad$ gravity acceleration

$G r_{x} \quad$ local Grashof number

$k \quad$ thermal conductivity $(\mathrm{W} / \mathrm{m} \cdot \mathrm{K})$

$t \quad$ time (s)

$T \quad$ temperature (K)

$u, v \quad$ velocity components along $x$ and $y$ axes $(\mathrm{m} / \mathrm{s})$

$x, y \quad$ cartesian coordinates (m)

Greek Symbols

$\alpha \quad$ thermal diffusivity

$\beta \quad$ thermal expansion

$\gamma \quad$ inclination angle

$\varepsilon \quad$ amplitude of modulation

$\eta \quad$ dimensionless similarity variable

$\theta \quad$ dimensionless temperature

$\lambda \quad$ mixed convection parameter

$\mu \quad$ dynamic viscosity

$\rho \quad$ density $\left(\mathrm{kg} / \mathrm{m}^{3}\right)$

$\tau \quad$ dimensionless time

$v \quad$ kinematic viscosity

$\phi \quad$ solid nanoparticles volume fraction

$\psi \quad$ stream function

$\Omega \quad$ non dimensional of frequency of oscillation

$\omega \quad$ dimensionless frequency of g-jitter oscillation

$\begin{array}{ll}\text { Subscripts } & \\ f & \text { base fluid } \\ s & \text { nanoparticles } \\ n f & \text { nanofluid } \\ \infty & \text { ambient environment }\end{array}$

\section{REFERENCES}

Anwar, I., Shafie, S. and Salleh, M.Z., 2014, "Radiation Effect on MHD Stagnation-Point Flow of a Nanofluid over an Exponentially Stretching Sheet," Walailak Journal of Science and Technology, 11(7), 569-591. http://dx.doi.org/10.14456/WJST.2014.11

Aurangzaib, Kasim, A.R.M., Muhammad, N.F., and Sharidan, S., 2013, "Unsteady MHD Mixed Convection Flow of a Micropolar Fluid along an Inclined Stretching Plate," Heat Transfer-Asian Research, 42(2), 899931. http://dx.doi.org/10.1002/htj.21034

Antar, B.N., and Nuotio-Antar, V.S., 1993, Fundamentals of Low Gravity Fluid Dynamics and Heat Transfer, CRC Press, Boca Raton.

Buongiorno, J., 2006, “Convective Transport in Nanofluids,” Journal of Heat Transfer, 128(3), 240-250. http://dx.doi.org/10.1115/1.2150834

Brinkman, H.C., 1952, “The Viscosity of Concentrated Suspensions and Solutions,” The Journal of Chemical Physics, 20(4), 571-571. http://dx.doi.org/10.1063/1.1700493

Chamkha, A.J. and Rashad, A.M., 2012, "Natural Convection from a Vertical Permeable Cone in a Nanofluid Saturated Porous Media for Uniform Heat and Nanoparticles Volume Fraction Fluxes,” International Journal of Numerical Methods for Heat and Fluid Flow, 22(8), 10731085. http://dx.doi.org/10.1108/09615531211271871

Choi, S.U.S, 1995, "Enhancing Thermal Conductivity of Fluids with Nanoparticles,” ASME-Publications, 231, 99-106.
Choi, S.U.S., Zhang, Z.G., Yu, W., Lockwood, F.E., and Grulke, E.A., 2001, "Anomalously Thermal Conductivity Enhancement in Nanotube Suspensions,” Applied Physics Letters, 79(14), 2252-2254. http://dx.doi.org/10.1063/1.1408272

Freidoonimehr, N., Rashidi, M.M., Mahmud, S., 2015, “Unsteady MHD Free Convective Flow past a Permeable Stretching Vertical Surface in a Nano-fluid,” International Journal of Thermal Science, 87, 136-145. http://dx.doi.org/10.1016/j.ijthermalsci.2014.08.009

Hirata, K., Sasaki, T., and Tanigawa, H., 2001, "Vibrational Effects on Convection in a Square Cavity at Zero Gravity,” Journal of Fluid Mechanics, 445, 327-334.

http://dx.doi.org/10.1017/S0022112001005651

Kasim, A.R.M., Mohammad, N.F., Aurangzaib, and Sharidan, S., 2012, "Natural Convection Boundary Layer Flow of a Viscoelastic Fluid on Solid Sphere with Newtonian Heating," World Academy of Science, Engineering and Technology, (64), 628-633.

Khan, W.A. and Pop, I., 2010, "Boundary-Layer Flow of a Nanofluid past a Stretching Sheet," International Journal of Heat and Mass Transfer, 53(11), 2477-2483.

http://dx.doi.org/10.1016/j.ijheatmasstransfer.2010.01.032

Khanafer, K., Vafai, K. and Lightstone, M., 2003, “Buoyancy-Driven Heat Transfer Enhancement in a Two Dimensional Enclosure Utilizing Nanofluids,” International Journal of Heat and Mass Transfer, 46(19), 3639-3653. http://dx.doi.org/10.1016/S0017-9310(03)00156-X

Kuznetsov, A.V., and Nield, D.A., 2010, "Natural Convective BoundaryLayer Flow of a Nanofluid past a Vertical Plate," International Journal of Thermal Sciences, 49(2), 243-247.

http://dx.doi.org/10.1016/j.ijthermalsci.2009.07.015

Mahdy, A., 2012, "Unsteady Mixed Convection Boundary Layer Flow and Heat Transfer of Nanofluids due to Stretching Sheet," Nuclear Engineering and Design, 249, 248-255.

http://dx.doi.org/10.1016/j.nucengdes.2012.03.025

Qasim, M., Khan, I. and Shafie, S., 2013, "Heat Transfer and Mass Diffusion in Nanofluids over a Moving Permeable Convective Surface,” Mathematical Problems in Engineering, 2013, 1-7. http://dx.doi.org/10.1155/2013/254973

Rawi, N.A., Kasim, A.R.M., Isa, M. and Sharidan, S., 2014, "g-Jitter Induced Mixed Convection Flow of Heat and Mass Transfer past an Inclined Stretching Sheet,” Jurnal Teknologi, 71(1), 27-31.

http://dx.doi.org/10.11113/jt.v71.3611

Rees, D.A.S. and Pop, I., 2000, “The Effect of g-Jitter on Vertical Free Convection Boundary Layer in a Porous Medium," International Communications in Heat and Mass Transfer, 27(3), 415-424. http://dx.doi.org/10.1016/S0735-1933(00)00122-6

Rees, D.A.S. and Pop, I., 2001, "g-Jitter Induced Free Convection near a Stagnation Point,” Heat and Mass Transfer, 37(4-5), 403-408. http://dx.doi.org/10.1007/s002310000178

Sharidan, S., Amin, N., and Pop, I., 2005, "The Effect of g-Jitter on Double Diffusion by Natural Convection from a Sphere,” International Journal of Heat and Mass Transfer, 48(21), 4526-4540.

http://dx.doi.org/10.1016/j.ijheatmasstransfer.2005.05.002

Sharidan, S., Amin, N., and Pop, I., 2006, "g-Jitter Mixed Convection adjacent to a Vertical Stretching Sheet," Microgravity-Science and Technology, 18(1), 5-14. http://dx.doi.org/10.1007/BF02908414

Sharidan, S., Amin, N., and Pop, I., 2007, "g-Jitter Free Convection Flow in the Stagnation Point Region of a Three Dimensional Body," Mechanics Research Communications, 34(2), 115-122.

http://dx.doi.org/10.1016/j.mechrescom.2006.05.004 
Tamim, H., Dinarvand, S., Hosseini, R., Khalili, S. and Pop, I., 2013, "Unsteady Mixed Convection Flow of a Nanofluid near Orthogonal Stagnation-Point on a Vertical Permeable Surface”, Proceedings of the Institution of Mechanical Engineers, Part E: Journal of Process Mechanical Engineering.

Tiwari, R.K. and Das, M.K., 2007, "Heat Transfer Augmentation in a Two-Sided Lid-Driven Differentially Heated Square Cavity Utilizing Nanofluids," International Journal of Heat and Mass Transfer, 50(9), 2002-2018. http://dx.doi.org/10.1016/j.ijheatmasstransfer.2006.09.034

Turkyilmazoglu, M, and Pop, I., 2013, "Heat and Mass Transfer of Unsteady Natural Convection Flow of Some Nanofluids past a Vertical Infinite Flat Plate with Radiation Effect," International Journal of Heat and Mass Transfer, 59, 167-171.

http://dx.doi.org/10.1016/j.ijheatmasstransfer.2012.12.009
Yirga, Y. and Shankar, B., 2015, "MHD Flow and Heat Transfer of Nanofluids through a Porous Media due to a Stretching Sheet with Viscous Dissipation and Chemical Reaction Effects," International Journal for Computational Methods in Engineering Science and Mechanics, 16(5), 275-284.

http://dx.doi.org/10.1080/15502287.2015.1048385

Uddin, M.J., Khan, W.A., and Amin, N.S., 2014, "g-Jitter Mixed Convective Slip Flow of Nanofluid past a Permeable Stretching Sheet embedded in a Darcian Porous Media with Variable Viscosity," PLOS ONE, 9(6), 1-12. http://dx.doi.org/10.1371/journal.pone.0099384

Uddin, M.J., Khan, W.A., and Ismail, A.I.M., 2015, “g-Jitter Induced Magnetohydrodynamics Flow of Nanofluid with Constant Convective Thermal and Solutal Boundary Conditions,” PLOS ONE, 2015, 1-15. http://dx.doi.org/10.1371/journal.pone.0099384
Vajravelu, K., Prasad, K.V., Lee, J., Lee, C., Pop, I. and Van Gorder, R.A., 2011, "Convective Heat Transfer In the Flow of Viscous Ag-Water and $\mathrm{Cu}-$ Water Nanofluids over a Stretching Surface,” International Journal of Thermal Sciences, 50(5), 843-851.

http://dx.doi.org/10.1016/j.ijthermalsci.2011.01.008

Wang, X., Xu, X., and Choi, S.U.S., 1999, "Thermal Conductivity of Nanoparticle-Fluid Mixture," Journal of Thermophysics and Heat Transfer, 13(4), 474-480. http://dx.doi.org/10.2514/2.6486 